\title{
A ASSOCIAÇÃO SIGNIFICANTE E SIGNIFICADO(S) A PARTIR DAS ACEPÇÕES \\ DO VERBETE GITANO,NA NO DICIONÁRIO DA REAL ACADEMIA ESPAÑOLA: SAUSSURE E BAKHTIN E SUAS NOÇÕES DE LÍNGUA
}

\section{THE SIGNIFICANT ASSOCIATION AND MEANING(S) FROM THE ACCEPTATIONS OF THE ENTRY GITANO, NA IN THE DICTIONARY OF THE ROYAL SPANISH ACADEMY: SAUSSURE AND BAKHTIN AND THEIR LANGUAGE CONCEPTS}

\author{
Cinara Leal Azevedo \\ Mestranda em Estudos Linguísticos pela Universidade Federal de Santa Maria (PPGL - UFSM) \\ E-mail: cici_azevedo@yahoo.com.br \\ Gabriela Colbeich da Silva \\ Mestranda em Estudos Linguísticos pela Universidade Federal de Santa Maria (PPGL - UFSM) \\ E-mail: gabi.colbeich@gmail.com
}

\section{RESUMO}

Neste artigo, a partir das noções saussureanas e bakhtinianas de língua, propomos-nos a examinar a situação apresentada em um vídeo intitulado \#YoNoSoyTrapacero \#YoNoSoyTrapacera, divulgado neste ano de 2015, pelo Consejo Estatal del Pueblo Gitano o qual faz parte de uma ação de sensibilização centrada na definição do verbete gitano,na na nova edição (23 $)$ do Diccionario de la Lengua Española, da Real Academia Española de la Lengua. No vídeo em questão, crianças ciganas, ao serem instigadas a ler as definições do verbete gitano,na nesse dicionário, não se mostram de acordo com a associação entre significante e significado presente em algumas acepções. A partir disso, podemos perceber que o dicionário não assegura a listagem de todas as relações possíveis entre a palavra e os conceitos aos quais remetem e, portanto, a afirmação presente no Curso de Linguística Geral (CLG) de que um dicionário e uma gramática possam representar uma língua de forma fiel (SAUSSURE, 2012) não se sustenta. Por conseguinte, necessitamos do apoio dos postulados de Bakhtin (2010), o qual acredita que todas as esferas da atividade humana, em suas variadas formas, estão sempre relacionadas com a utilização da língua, contrapondo-se a concepção de língua enquanto sistema de regras. Dessa forma, Bakhtin (2010), ajuda na compreensão das discrepâncias existentes entre as representações da palavra gitano,na.

Palavras-chave: Dicionário. Gitano,na. Língua. Saussure. Significação. 


\section{ABSTRACT}

In this article, from Saussurean and Bakhtinian language notions, we propose us to examine the situation presented on a video entitled \#YoNoSoyTrapacero \#YoNoSoyTrapacera, released in this year of 2015, by the Consejo Estatal del Pueblo Gitano which is part of an awareness action focused in the definition of gitano,na entry in the new edition (23th) of the Diccionario de la Lengua Española, of the Real Academia Española de la Lengua. On this video, gypsy children when instigated to read the definitions of the gitano, na entry, in this dictionary, they are not shown accordning to the association between signifier and signified, present in some acceptations. From this, is perceptible that the dicctionary does not guarantee the listing of all possible relationships between the word and concepts to which they refer and thus, the affirmation in the Course in General Linguistics (CGL) that a dictionary and a grammar can represent a faithful form of language (Saussure, 2012) does not hold. Therefore, we need the support of the postulates of Bakhtin (2010), which believes that all spheres of human activity, in its various forms, are always related to the use of language, in contrast to the conception of language as a system of rules. Thus, Bakhtin (2010), helps in the comprehension of discrepancies between representations of the word gitano,na.

Key-words: Dictionary. Gitano,na. Language. Saussure. Signification

\section{INTRODUÇÃO}

De acordo com Rodrigues (2008) pode-se afirmar que todo o conhecimento sobre linguagem produzido no século XX teve origem na obra Curso de Linguística Geral surgida na França em 1916. A referida obra é uma homenagem póstuma ao linguista Ferdinand de Saussure. Saussure foi professor da Universidade de Genebra, onde ministrou três cursos, conhecidos como Cours de Linguistique Générale, os quais o consagraram no âmbito dos estudos da linguagem. O primeiro em 1907, o segundo de 1908 a 1909 e o terceiro de 1910 a 1911. Saussure, permaneceu na Universidade de Genebra até sua morte, em 1913. Três anos depois, em 1916, os cursos resultaram na publicação da primeira edição do Curso. Os organizadores da obra foram Charles Bally e Albert Sechehaye, que realizaram uma compilação das anotações pessoais do linguista e dos alunos que assistiram aos cursos, com contribuição especial de Albert Riedlinger.

O livro "Curso de Linguística Geral” (CLG) é tido como um clássico, conforme aponta Isaac Nicolau Salum, no Prefácio à Edição Brasileira "não é uma "bíblia" da Linguística moderna, que dê a última palavra sobre os fatos, mas é ainda o ponto de partida de uma 
problemática que continua na ordem do dia”. (SAUSSURE, p. XV, 2006). É nessa obra que Saussure consegue estabelecer um objeto (a língua) e um método (o sistema) próprio para a Linguística, que a eleva ao status de ciência autônoma.

Entretanto, ao analisar mais cuidadosamente as postulações de Saussure, nos deparamos com algumas divergências no que se refere ao uso da língua pelos falantes, como é o caso, por exemplo, da dicotomia significado $\mathrm{x}$ significante.

Ao buscar a definição de uma palavra no dicionário pode ser que tal definição não faça parte do imaginário a que nos remete. Esse é o caso, por exemplo, do conceito da palavra gitano,na ${ }^{1}$ encontrado no dicionário da Real Academia Española (RAE) com uma definição na qual o povo cigano não se reconhece e não se mostra de acordo com a associação entre significante e significado abordado nas acepções.

Desse modo, o dicionário não assegura a relação entre as palavras e as coisas que elas significam, não sendo um lugar de transparência. Portanto, o que nos propomos nesse trabalho é investigar, com base nos conceitos de Saussure (2006, 2012) e Bakhtin (2010) de que modo podemos tentar compreender tal fato a partir das postulações destes dois autores.

\subsection{REAL ACADEMIA ESPAÑOLA DE LA LENGUA (RAE) E SEU DICIONÁRIO}

A Real Academia Española (RAE) foi criada em Madri em 1713, por iniciativa de Juan Manuel Fernández Pacheco y Zúñiga (1650-1725), oitavo marquês de Vilhena, que também foi seu primeiro diretor. A RAE, cujo principal precedente e modelo foi a Academia Francesa fundada pelo cardeal Richelieu em 1635, tomou como objetivo essencial desde sua criação a elaboração de um dicionário da língua espanhola, o mais extenso que pudesse ser feito.

Esse propósito se fez real com a publicação do Diccionario de autoridades, editado em seis volumes, entre 1726 e 1739, e em cujo começo se inclui uma breve história da corporação. Em 1715, a Academia, que no começo contava com vinte e quatro membros, aprovou seus primeiros estatutos, a que seguiram os de 1848, 1859, 1977 e 1933. A Orthographía surgiu em 1741 e em 1771 foi publicada a primeira edição da Gramática.

Instalada em sua atual sede acadêmica em Madri desde 1894, a instituição foi adaptando suas funções às necessidades e exigências da sociedade de seu tempo. Os estatutos vigentes, aprovados em 1993, estabelecem como objetivo fundamental da Academia velar por que la lengua española, en su continua adaptación a las necessidades de los hablantes, no quiebre su esencial unidad. Este compromisso se materializou na denominada política linguística panhispânica, compartilhada com as outras vinte e uma corporações que fazem parte da Associação de Academias da Língua Espanhola (ASALE), criada no México em 1951. 
O Diccionario de la Lengua Española é a obra lexicográfica acadêmica por excelência. O repertório começa em 1780, com o surgimento - em um único volume para facilitar sua consulta - de uma nova versão do primeiro dicionário da instituição que foi o precendente da série de dicionários usuais que tem hoje.

A partir de então, foram publicadas vinte e três edições da obra, transformada, com o passar do tempo, no dicionário de referência e consulta da língua espanhola. O dicionário é resultado da colaboração de todas as academias, cujo propósito é coletar o léxico geral utilizado na Espanha e nos países de língua espanhola. Dirige-se, fundamentalmente, a falantes cuja língua materna é o espanhol, que encontrarão nele recursos suficientes para decifrar textos escritos e orais. Desde 2001 o dicionário possui uma versão de consulta online gratuita à qual vem sendo incorporada uma parte das modificações aprovadas pelas academias.

É importante salientar que, o estabelecimento de um dicionário, como o proposto pela RAE, está ligado ao processo de gramatização da língua. Segundo Auroux (1992, p. 65) “[...] por gramatização deve-se entender o processo que conduz a descrever e a instrumentar uma língua na base de duas tecnologias, que são ainda hoje os pilares de nosso saber metalinguístico: a gramática e o dicionário". Trazer esta definição é tributar a Auroux o mérito de possibilitar pensar no processo de gramatização de uma língua.

\subsection{O DICIONÁRIO}

A história dos dicionários teve início na Grécia Antiga, onde era realizado o registro das palavras em uso através de listas. A forma de dicionário como conhecemos hoje, levou milhares de anos para se consolidar. Assim, "foram necessários séculos para a passagem das primeiras listas de palavras (a partir de 3.000 a.C.) aos glossários medievais e depois aos dicionários monolíngues das línguas nacionais a partir do século XVI” (NUNES, 2002, p. 101).

Segundo Bagno e Rangel (2006), os primeiros dicionários teriam sido elaborados com dois tipos diferentes, mas associados, de objetivos. Num primeiro caso, os propósitos eram eminentemente didáticos: estabelecer equivalências entre palavras do latim (e, às vezes, do grego) e de línguas modernas como o espanhol, o francês e o português. Era uma forma de facilitar o acesso dos alunos aos textos clássicos estudados nas universidades.

O segundo objetivo era sistematizar, ao lado das então recentes gramáticas de línguas modernas, o conhecimento de línguas cujas nações lançavam-se à conquista de outros povos. Nesse sentido, gramáticas e dicionários de línguas como o espanhol serviam para propiciar e estabelecer uma espécie de consenso sobre que variedade da língua seria imposta e ensinada aos 
conquistados. Por outro lado, esse saber linguístico poderia ser mobilizado para que os próprios espanhóis descrevessem e aprendessem as línguas desses mesmos povos, para tornar possível, entre outros empreendimentos decorrentes da conquista, a catequese (BAGNO e RANGEL, 2006).

Por meio das palavras registradas nessas listas, essas sociedades pretendiam conhecer melhor tanto as coisas do mundo quanto as próprias palavras que utilizavam para designá-las. De alguma forma, esta ainda é a dupla orientação dos dicionários contemporâneos: o primeiro caso é o da preocupação enciclopédica, que leva os dicionários a associar a cada palavra registrada o máximo possível de informações a respeito da coisa que ela designa; o segundo caso é o da orientação linguística, que procura revelar de que forma estão organizadas na língua as palavras repertoriadas. Assim, uma palavra como ‘cigano' virá associada, num dicionário, a informações tanto relativas ao conceito (significado) - indivíduos de um povo originário da Índia, por exemplo, - quanto à imagem acústica (significante): substantivo masculino, adjetivo, etc.

De acordo com Bagno e Rangel (2006), o que distingue o dicionário de outros gêneros é exatamente essa dupla aposta no poder da palavra e, portanto, o seu estreito compromisso com o léxico, que ele pretende inventariar e descrever. Na qualidade de componente de uma língua, o léxico pode ser definido, inicialmente, como o conjunto de todos os vocábulos de que essa língua dispõe. De forma geral, é nesses termos que ele vem definido em boa parte das gramáticas escolares, mas também em muitos manuais e dicionários de linguística. Já nesse primeiro entendimento, portanto, o léxico é uma abstração, ou melhor, uma reconstrução teórica do mundo das palavras, a partir de experiências concretas sempre limitadas.

De forma simplista, “[...] o dicionário é uma lista de palavras, com definições e exemplos." (NUNES, 2010, p. 6). É um instrumento ao qual, frequentemente, recorre-se quando não se tem domínio ou conhecimento sobre o significado de um vocábulo de uma língua. Portanto, raramente, são questionadas as definições ali apresentadas.

Entretanto, ao considerá-lo desde o ponto de vista daqueles que fazem uso das diversas línguas, a concepção de "verdade absoluta" se desfaz. Partindo dessa compreensão, “[...] não há uma leitura única do dicionário, assim como não há sentidos das palavras fixados eternamente. Os sentidos sempre podem ser outros e assim também as leituras.” (NUNES, 2010, p. 12).

A língua, na perspectiva discursiva, oferece diversas possibilidades de visualização, o que pode gerar uma distinção entre o que está posto na língua e o saber institucionalizado através do dicionário, por exemplo. Conforme Petri (2010), é no uso da língua que esses dois saberes entrarão em relação, revelando contradições, distanciamentos e aproximações.

Ao considerar as acepções usadas pelo lexicógrafo, Nunes (2010), salienta que 
as definições, do ponto de vista discursivo, não são neutras, elas são sempre efetuadas a partir de uma posição discursiva, que pode não coincidir com a posição que ocupa o leitor. Além disso, as definições se tornam desatualizadas em relação aos discursos em circulação (NUNES, 2010, p. 13).

Ninguém se depara, no uso cotidiano de uma língua, com todas as suas palavras. O que de fato testemunhamos, nas diferentes situações de comunicação, é o vocabulário efetivamente empregado por cada usuário com que temos contato. Nesse vocabulário, há termos de uso comum, que todos, em princípio, dominam. Outros termos são usados e/ou conhecidos apenas em determinadas circunstâncias, ou predominantemente por um tipo particular de pessoa (crianças, idosos, homens, mulheres), em determinadas camadas sociais ou em certas regiões.

Assim, nenhum falante é capaz de empregar ou mesmo reconhecer e compreender todas as palavras de sua língua, nem dominar todos os recursos de comunicação e expressão de que elas dispõem. Mas é essa experiência individualmente limitada com os vocábulos que nos permite apreender sua natureza e sistema e entender de que maneira funcionam, em nossa língua, os mecanismos que nos permitem criar e utilizar palavras. É essa experiência que nos faz perceber a distância entre o vocabulário que conhecemos e dominamos e as demais palavras que circulam na comunidade linguística de que fazemos parte.

O léxico, mesmo em sua dimensão de conjunto das palavras disponíveis em uma língua, é, antes de mais nada, uma rede de funções e de relações de forma e de sentido entre vocábulos, e não uma simples lista de itens. Isso porque no domínio do léxico nenhuma unidade está isolada das demais (BAGNO e RANGEL, 2006).

\subsection{A CAMPANHA \#YONOSOYTRAPACERO \#YONOSOYTRAPACERA}

Em 8 de abril, comemora-se o Día Internacional del Pueblo Gitano (International Roma Day). Esta data relembra o Congresso Mundial roma/cigano celebrado em Londres, nesta mesma data, no ano de 1971, em que se instituiu a bandeira e o hino ciganos.

Há alguns anos, o 8 de abril está adquirindo grande notoriedade, servindo de ocasião para diferentes celebrações e comunicações por parte de várias instituições europeias. Uma data para celebração, para tornar mais visível a unidade a diversidade dos ciganos e ciganas de todo o mundo e os seus importantes aportes à cultura universal. Um dia para promover a solidariedade, o apoio e o afeto da sociedade inteira. Uma data também para recordar a história do povo cigano e seu percurso europeu desde a Índia e para que aqueles ciganos e ciganas que foram vítimas do genocídio nazista e de diferentes perseguições ao longo dos séculos não sejam esquecidos (FUNDACIÓN SECRETARIADO GITANO, 2015).

Linguagens - Revista de Letras, Artes e Comunicação ISSN 1981-9943 Blumenau, v. 11, n. 1, p. 375-389, jan./abr. 2017 
Neste ano, 2015, as entidades que fazem parte do Consejo Estatal del Pueblo Gitano realizaram uma ação de sensibilização centrada na definição do verbete gitano,na na nova edição (23 $)$ do Diccionario de la Lengua Española, da Real Academia Española (RAE), com o lema Una definición discriminatória genera discriminación. De acordo com a Fundación Secretariado Gitano, há muitos anos, desde a criação de organizações e instituições governamentais e não governamentais, vem-se solicitando à RAE que revisasse as definições de gitano,na em seu dicionário, visto que, por exemplo, na edição anterior (22 $)$ na quarta acepção lia-se o seguinte: "que estafa u obra com engano". No final de 2014, a Academia publicou uma nova edição do dicionário em que esta acepção foi substituída por uma nova: trapacero, que o próprio dicionário descreve como aquela pessoa "que con astucias, falsedades y mentiras procura engañar a alguien en un asunto".

O lema da campanha explica a importância da linguagem para construir uma imagem social da comunidade cigana que esteja distante dos estereótipos. A peça principal da campanha é um vídeo de dois minutos protagonizado por algumas crianças ciganas, meninos e meninas, e sua reação de surpresa ao descobrir o significado que o dicionário dá ao termo em questão. Além do vídeo, foram editados cartazes, panfletos, marca páginas, etc. A campanha foi lançada através das redes sociais com as hashtags \#YoNoSoyTrapacero e \#YoNoSoyTrapacera e o vídeo obteve uma grande repercussão nos principais meios de comunicação, principalmente nos espanhóis (FUNDACIÓN SECRETARIADO GITANO, 2015).

\section{REFERENCIAL TEÓRICO}

\subsection{OBJETIVISMO ABSTRATO E SAUSSURE: NOÇÕES BASILARES}

No começo do século XX, o pensamento filosófico-linguístico encontrava-se em presença e primazia de duas orientações no que concernia ao isolamento e à delimitação da linguagem como objeto de estudo: o subjetivismo idealista e o objetivismo abstrato (BAKHTIN, 2010). Destas, Ferdinand de Saussure foi a figura de maior relevância da segunda orientação.

Adotando como base as dicotomias saussurianas, o objetivismo abstrato entende a língua como algo social, de conhecimento generalizado, e a aborda como um sistema psíquico e arbitrário. Com base nesse ponto de vista, o indivíduo receberia passivamente, da sua comunidade, um sistema linguístico pronto, estável e imutável, que dispõe de signos e regras, no qual ele não poderia interferir conscientemente (BAKHTIN, 2010). 
O que encontramos nessa orientação é o domínio da estrutura linguística, imanente, sobre o sujeito. Ao contrário do subjetivismo idealista, que destaca como fonte da língua o psiquismo individual, para o objetivismo abstrato, a essência da língua encontra-se no próprio sistema. O centro organizador de todos os fatos da língua está no sistema linguístico, no sistema das formas fonéticas, gramaticais e lexicais. Dessa maneira, a língua se compõe de signos, idênticos e normativos, que servem como instrumento para a comunicação entre os sujeitos, que garantem a compreensão da palavra por todos os que dela fazem uso (BAKHTIN, 2010).

As formas normativas, responsáveis pelo imobilismo do sistema linguístico, não eram, para o subjetivismo idealista, senão resíduos deteriorados da evolução linguística, da verdadeira substância da língua, tornada viva pelo ato de criação individual e único. Contudo, para o objetivismo abstrato, é justamente este sistema de formas normativas que se torna substância da língua. A refração e a variação de caráter individual e criador das formas (de seu imobilismo), harmônicos inúteis e intangíveis do tom fundamentalmente estável das formas linguísticas (BAKHTIN, 2010).

Ferdinand de Saussure mostra-se como a mais brilhante expressão do objetivismo abstrato, contemporaneamente, ao fornecer o esclarecimento das ideias dessa orientação e ao precisa-las. O linguista suíço partiu do princípio de uma tríplice distinção: langage, langue (sistema de formas) e parole (ato individual, fala). A língua e a fala são os elementos constitutivos da totalidade, sem exceções, de todas as manifestações físicas, fisiológicas e psíquicas que fazem parte da comunicação linguística, ou seja, língua e fala são elementos da linguagem (SAUSSURE, 2012).

Com o objetivo de tornar a Linguística uma ciência independente, Saussure, procura um objeto passível de ser estudado. Inicialmente, ao tentar definir a linguagem e os fatores constituintes desta, afirma que ela não serve como objeto de estudo devido a seu caráter heteróclito e multifacetado e por pertencer a vários domínios. Isso ocorre pois os fatores que a constituem são, ao mesmo tempo, de cunho social (língua) e individual (fala) e, ainda que um não possa ser concebido sem o outro, a linguagem carece de unidade interna e de leis independentes e autônomas (SAUSSURE, 2012).

Tem-se então a primeira distinção, língua $x$ fala. Saussure vê a língua como algo que ultrapassa o individual, ou seja, é um sistema utilizado como meio de comunicação entre indivíduos de uma mesma comunidade linguística. Na compreensão saussuriana, é na língua que está a essência da linguagem, por esta fazer parte do produto social, por ser homogênea e estável e por ser um produto que o indivíduo registra passivamente (SAUSSURE, 2012). 
A língua, dessa forma, impõe-se ao sujeito, pois é um sistema que este não pode criar nem modificar, visto que é um sistema acabado, dado ao indivíduo por sua comunidade. Esse sistema linguístico é composto por leis imanentes que não podem sofrer influências das leis tidas como ideológicas, justamente por aquelas serem mais perenes que estas.

Saussure considerava impraticável, no início do século XX, uma Linguística da fala, porque na fala não se pode estabelecer de quais signos o indivíduo irá se valer no momento da enunciação. Em outras palavras, a fala não servia como objeto de estudo da linguística por se constituir de elementos individuais, assistemáticos e ilimitados. Para Saussure, o fator sistemático da linguagem estava presente na língua.

Isolado o objeto, Saussure se dedica ao estudo e análise da língua por meio de uma análise sincrônica, sem levar em consideração os fenômenos extralinguísticos e históricos. O genebrino opta pela análise sincrônica, pois, segundo ele, o escopo da linguística estrutural é observar as relações internas do sistema linguístico em um determinado momento do tempo. Esse tipo de estudo nos remete a um modo de ver a língua como algo estático, enquanto na diacronia se percebe a língua em desenvolvimento, em efervescência.

Ainda nas dicotomias saussurianas (SAUSSURE, 2012), na composição dos signos, encontramos a distinção entre significante e significado. O ponto de partida do circuito da fala se situa no cérebro de cada pessoa, "os fatos de consciência, a que chamaremos conceitos, se acham associados às representações dos signos linguísticos ou imagens acústicas que servem para exprimi-los" (SAUSSURE, 2012, p. 43).

Saussure diz que todo signo linguístico tem essas duas faces que não podem ser isoladas. O significante está relacionado à imagem acústica (som), enquanto o significado referese ao conceito (ideia). Com essa conceituação do que é significante e significado, Saussure diz que o signo linguístico é arbitrário e convencional, já que não é necessário haver uma relação de sentido entre a imagem acústica e o conceito em determinado signo.

\subsection{O DICIONÁRIO E A REPRESENTAÇÃO DE LÍNGUA PARA SAUSSURE: SIGNIFICAÇÃO}

No CLG, sustenta-se a afirmação de que entre os indivíduos unidos pela linguagem se estabelece um tipo de meio-termo que todos reproduzem, não de modo rigorosamente idêntico, mas aproximadamente, os mesmos signos, com as mesmas associações entre os significantes e seus significados. Dessarte, somente as vinculações consagradas e fixadas pela língua parecem estar de acordo com a realidade.

Os signos linguísticos não são abstrações para Saussure (2012), apesar de serem, fundamentalmente, psíquicos. As associações entre significado e significante, legitimadas pelo coletivo e cujo conjunto constitui a língua, são realidades que têm sua sede no cérebro. Podemos, 
inclusive, fixar os signos da língua em imagens convencionais por meio da escrita devido a sua palpabilidade. A significação é resultante da unidade linguística, que é uma coisa dupla, uma entidade psíquica, constituída da união, acordada pela massa falante em cada sistema linguístico, de dois termos. Saussure designou como signo (o total) a combinação de conceito (significado) e de imagem acústica (significante).

Na língua, se se faz abstração da infinidade de movimentos necessários para realizar a fonação, cada imagem acústica se restringe à soma de um número limitado de elementos ou fonemas, suscetíveis de serem evocados por um número correspondente de signos na escrita. Dessa forma, para Saussure (2012), é justamente "essa possibilidade de fixar as coisas relativas à língua que faz com que um dicionário e uma gramática possam representa-la fielmente, sendo ela o depósito das imagens acústicas e a escrita a forma tangível dessas imagens" (SAUSSURE, 2012, p. 47).

Socialmente, a língua é resultado da soma de signos depositados no cérebro de cada falante, como se esta fosse "um dicionário cujos exemplares, todos idênticos, fossem repartidos entre os indivíduos" (SAUSSURE, 2012, p. 51). Trata-se, pois, de algo que está em cada um e, embora comum a todos, não depende da vontade de seus depositários. Somente no conjunto da massa é que o sistema da língua existe de modo completo.

Desde a perspectiva saussuriana, a língua não é uma função de responsabilidade do falante, este somente a registra passivamente. $\mathrm{O}$ vínculo social que constitui a língua, somente pode ser circundado virtualmente a partir do sistema presente e armazenado pelas imagens verbais no cérebro de cada indivíduo, do conjunto de indivíduos (SAUSSURE, 2012).

$\mathrm{O}$ indivíduo tem que tomar e assimilar o sistema no seu conjunto, tal como ele lhe foi dado. Não há lugar para distinções ideológicas de caráter apreciativo, só existe o critério linguístico de acerto ou erro dentro do sistema normativo da língua. Não se poderia, por conseguinte, falar de preferências, nem de verdades linguísticas. Do ponto de vista do indivíduo, as leis linguísticas são arbitrárias, privadas de uma justificação natural ou ideológica (BAKHTIN, 2010).

\subsection{O DICIONÁRIO E A REPRESENTAÇÃO DE LÍNGUA PARA BAKHTIN: O CONTRAPONTO}

Contemporâneo à Saussure, Bakhtin antecipa a Linguística Moderna. Concorda com o genebrino que a língua é um fato social fundado na necessidade de comunicação, entretanto, contrapondo-se a ele, critica a concepção de língua enquanto sistema de regras. Acredita que todas as esferas da atividade humana, em suas variadas formas, estão sempre relacionadas com a utilização da língua (BAKHTIN, 2010). 
Para Bakhtin (2010, p. 128), “a língua vive e evolui historicamente na comunicação verbal concreta, não no sistema linguístico abstrato das formas da língua, nem no psiquismo individual dos falantes”. Logo, para o autor, a substância da língua é constituída pelo fenômeno social da interação verbal realizada através das enunciações.

A língua não é apresentada por Bakhtin como objeto abstrato, mas como atividade social, fundada nas necessidades de comunicação, assim, a natureza da língua seria essencialmente dialógica, pois "tudo que é ideológico possui um significado e remete a algo situado fora de si mesmo. Em outros termos, tudo que é ideológico é um signo. Sem signos não existe ideologia”. (BAKHTIN, 2010, p. 29).

Ela seria a "expressão das relações e lutas sociais, veiculando e sofrendo o efeito desta luta, servindo, ao mesmo tempo, de instrumento e de material” (BAKHTIN, 2010, p. 17). A língua em uso, de acordo com a consciência linguística dos interlocutores, não se relaciona, desde a perspectiva bakhtiniana, com um sistema abstrato de formas normativas, mas com a linguagem no sentido de conjunto dos contextos possíveis de uso de cada forma particular. Essa consciência linguística não tem o que fazer com a forma linguística enquanto tal, nem com a própria língua como tal (BAKHTIN, 2010).

De fato, a forma linguística sempre se apresenta aos locutores no contexto de enunciações precisas, o que implica sempre um contexto ideológico preciso. $\mathrm{Na}$ realidade, não são palavras que se pronunciam ou se escutam, pois a palavra está sempre carregada de um conteúdo ou de um sentido ideológico ou vivencial. Em vista disso, Bakhtin (2010) critica o modo próprio do objetivismo abstrato de estudar a língua, no qual é dado destaque para a forma linguística sem levar em consideração os sujeitos no momento da enunciação. Dessa maneira, o sentido de uma palavra só pode ser compreendido quando considerado seu contexto real de uso, isto é, uma palavra ganha diferentes sentidos quando usada em situações distintas.

Desde essa perspectiva, segundo Bakhtin (2010), o falante nativo não identifica a palavra como um item de dicionário, mas como parte das mais diversas enunciações dos locutores de sua comunidade e das múltiplas enunciações de sua própria prática linguística. Para que se passe a perceber a palavra como uma forma fixa pertencente ao sistema lexical de uma língua dada (como uma palavra de dicionário) é preciso que se adote uma orientação particular e específica. É por isso que os membros de uma comunidade linguística, normalmente, não percebem nunca o caráter coercitivo das normas linguísticas. A significação normativa da forma linguística só se deixa perceber nos momentos de conflito, momentos raríssimos e não característicos do uso oral da língua (BAKHTIN, 2010). 


\title{
3 ANÁLISE DA CAMPANHA \#YONOSOYTRAPACERO \#YONOSOYTRAPACERA
}

A campanha \#YoNoSoyTrapacero \#YoNoSoyTrapacera, realizada em abril de 2015, traz uma discussão sobre a definição do termo gitano,na, apresentada no dicionário da Real Academia Española (RAE), no qual o verbete aparece definido a partir das seguintes acepções:

\begin{abstract}
gitano, na. (De egiptano, porque se creyó que procedían de Egipto). 1. adj. Dicho de una persona: De un pueblo originario de la India, extendido por diversos países, que mantienen en gran parte un nomadismo y han conservado rasgos físicos y culturales propios. U. t. c. s. \| 2. Perteneciente o relativo a los gitanos. 3. adj. Propio de los gitanos, o parecido a ellos. \| 4. caló (Perteneciente al caló) - Léxico gitano \| 5. trapacero. U.t.c.s 6. Coloq. Que tiene gracia y arte para ganarse las voluntades de otros. U. más como elogio, y especialmente referido a una mujer. U. t. c. s. 7. adj. desus. egipcio (\| natural de Egipto). Era U.t.c.s. 6. m. caló. (variedad del romaní) que no se lo salta un $\sim$. 1. expr. coloq. U. para ponderar lo grande o extraordinario en cualquier aspecto. (RAE, 2014, p.1138).
\end{abstract}

O vídeo da campanha retrata a não aceitação da veiculação de estereótipos pelo dicionário e, principalmente, a discordância de um povo com relação a um dos significados atribuídos ao vocábulo gitano,a na definição apresentada pela RAE: trapacero. Assim, há um distanciamento produzido pelo significado institucionalizado e a representação da palavra no imaginário daquela comunidade. Vemos que o sentido da palavra se escapa, apresentando uma incompletude, uma falha na definição exposta pelo dicionário.

A campanha alerta ainda, para os usos discriminatórios, preconceituosos e pejorativos empregados na definição do termo gitano,na ao classificá-los como astutos, enganadores, falsos e mentirosos. Isso cria um imaginário coletivo no qual os povos de origem cigana tendem a ser vistos como pessoas negativas, apagando os sentidos "positivos" que estão por traz da imagem.

Quanto à questão ideológica, Borba expõe que "não existe texto neutro quanto à ideologia", ou seja, "quem fala ou escreve pretende sempre colocar [sugerir, propor, impor, inculcar], mesmo que implicitamente seu modo de ver e sentir o universo" (2003, p. 307). Desse modo, o dicionário da RAE faz uma escolha ideológica ao optar por apresentar definições de caráter depreciativo, cristalizadas há séculos e que não condizem com a representação da significação que a própria comunidade se atribui.

Portanto, ao considerar as definições expostas nos dicionários, é preciso

[...] saber que há certos sentidos que aparecem e se sedimentam, se estabilizam, mas ao mesmo tempo é saber que eles sempre estão sujeitos a serem outros, sempre estão sujeitos aos equívocos, aos deslizamentos de sentido, às contradições entre diferentes posições de leitura (NUNES, 2010, p. 12). 
É relevante considerar, como também aponta Nunes (2010), que a sociedade muda, os sentidos mudam, mas que o dicionário pode manter um imaginário que já não se sustenta. Por isso, as entidades que fazem parte do Consejo Estatal del Pueblo Gitano realizaram a ação de sensibilização contra a definição do verbete gitano,na na atual edição do dicionário da RAE.

As entidades pretendem estabelecer um novo acordo entre significado(s) e significante, uma nova representação. A significação do termo para os ciganos é diferente daquela acordada pela sociedade em geral e daquela circunscrita pelo dicionário. A mudança na associação entre conceito e imagem de um dos elementos do sistema da língua que se solicita na campanha, de acordo com os pressupostos saussurianos, modificaria não só o elemento em questão, mas criaria um novo sistema (BAKHTIN, 2010).

Contudo, para Saussure, as relações que existem entre duas formas linguísticas no sistema (em sincronia), nada têm em comum com as relações que unem qualquer destas formas à sua imagem transformada nos diferentes estágios de desenvolvimento histórico da língua (em diacronia). O que torna a língua significante e coerente no quadro sincrônico é excluído e inútil no quadro diacrônico. O presente da língua e sua história não se entendem entre si, são ambos incapazes de se entenderem.

\section{CONSIDERAÇÕES FINAIS}

Na medida em que procuram registrar o maior número possível de palavras da língua escrita e falada e se esforçam por reunir a seu respeito o máximo de informações pertinentes, os dicionários são servidores de muitos patrões. Servem a todas e a cada uma das especialidades com que convivemos; e assim, devem fidelidade ao cotidiano de usuários muito diferentes. Por isso mesmo, registram e explicam o que significam e como funcionam - ou seja, o que valem - as palavras que designam as mais variadas coisas que existem à nossa volta (léxico), assim como as que servem para pôr a língua em funcionamento, organizar o discurso e estabelecer relações entre suas partes (gramática).

O léxico é um componente dinâmico e aberto, novas palavras surgem e palavras já existentes se ressignificam, a todo momento, para suprir necessidades de expressão também novas. Ao mesmo tempo, outros vocábulos entram em processo de desuso até se converterem em arcaísmos. Portanto, nenhum dicionário, por mais exaustivo que se pretenda em sua cobertura e descrição, atinge efetivamente a completude.

Podemos alegar que, no léxico, um vocábulo não é isso ou aquilo, mas está nesse ou naquele conjunto de relações; portanto, tal como acontece com a moeda, seu valor efetivo só se estabelece na hora do uso. O léxico, considerado tanto abstração do falante leigo quanto 
(re)construção do linguista ou lexicógrafo, é sempre uma representação possível da realidade da língua, e não a própria língua. Desta forma, o léxico será retratado de formas muito diversas num dicionário, em função da concepção de língua e de léxico que o dicionarista adota, de seu interesse maior ou menor pela língua atual, por sua decisão de privilegiar ou não a norma culta, de favorecer ou não certa variante regional, de incluir ou não gírias, neologismos e empréstimos recentes etc.

Com base nessas considerações, é possível verificar que qualquer dicionário não consegue representar, fidedignamente, uma língua em seu todo, pois logra apresentar apenas algumas das relações possíveis de significação entre conceito e imagem acústica. Nesse sentido, o exposto no CLG permite críticas uma vez que nele um dicionário ou uma gramática podem representar fielmente uma língua o que, como se pôde esboçar aqui, não é factível.

Bakhtin critica esse modo de estudar a língua, próprio do objetivismo abstrato, no qual é dado destaque para a forma linguística sem levar em consideração os sujeitos no momento da enunciação. Para Bakhtin, o sentido de uma palavra só pode ser compreendido quando considerado seu contexto de uso, isto é, uma palavra ganha diferentes sentidos quando usada em situações distintas. Dentre as críticas ao objetivismo abstrato, está a que se refere ao caráter imutável da língua estabelecido nessa teoria. O filósofo russo diz que a língua sofre alterações mesmo quando analisada sincronicamente, porque está num eterno devir.

Devido à imutabilidade do sistema dos signos linguísticos, de acordo com a perspectiva saussuriana, seria impossível que a comunidade cigana, por si só, modificasse a relação significado e significante do termo em questão. Somente se o todo da massa social desvinculasse o significante gitano,na do significado trapacero é que se decomporia essa associação do sistema.

A mudança na associação entre conceito e imagem de um dos elementos do sistema da língua que se solicita na campanha, de acordo com os pressupostos saussurianos, modificaria não só o elemento em questão, mas criaria um novo sistema (BAKHTIN, 2010). Só a partir desse acordo entre a massa de usuários da língua é que se autorizaria essa nova relação a fazer parte do sistema.

Com base no exposto, podemos perceber que o objetivismo abstrato, e inclusive o subjetivismo idealista, deixou de abordar aspectos importantes da linguagem. Ao dar ênfase ao caráter sistemático das línguas, negligenciou a interação verbal, aspecto central para a compreensão da linguagem discursiva, que não pode ser entendida sem levar em conta sua dupla face: a social e a individual. Partilhamos da perspectiva bakhtiniana (2010) de que toda modificação ideológica desencadeia uma modificação da língua, pois todo signo, por ser ideológico, reflete as estruturas sociais das quais compartilha. 


\section{NOTA}

1 Neste artigo, fazemos uso do termo gitano,na para remeter à maneira como o vocábulo é citado dentro do Dicionário da RAE.

\section{REFERÊNCIAS}

AUROUX, S. (1992). A revolução tecnológica da gramatização. Trad. por Eni Puccinelli Orlandi. Campinas, SP: Editora da UNICAMP.

BAHKTIN, M. (VOLOCHÍNOV, V.) (1929). Marxismo e Filosofia da Linguagem: problemas fundamentais do método sociológico da linguagem. São Paulo: Hucitec, 2010.

BORBA, F. S. (2003). Organização de dicionários: uma introdução à lexicografia. São Paulo: UNESP.

CONSEJO ESTATAL DEL PUEBLO GITANO. Acción de sensibilización \#YoNoSoyTrapacero\#YoNoSoyTrapacera. Disponível em: $<$ http://actualidad.rt.com/videocl ub / 171518-reaccion-ninos-gitanos-leer-rae>. Acesso em: 01 jun. 2015.

BAGNO, M; RANGEL, E. O. Dicionários em sala de aula. Brasília: Ministério da Educação e Secretaria da Educação Básica, 2006. Disponível em: <http://portal.mec.gov.br/seb/arquivos/pdf/ Avalmat/polleidicio.pdf $>$. Acesso em: 01 jun. 2015.

FUNDACIÓN SECRETARIADO GITANO. Fundación Secretariado Gitano - Gitanos. Disponível em: <https://www.gitanos.org/actualidad/dossieres/110637.html>. Acesso em: 01 jun. 2015.

NUNES, H. Dicionários: história, leitura e produção. In: ENCONTRO DE LETRAS DA UNIVERSIDADE CATÓLICA DE BRASÍLIA, 8, 2010. Anais eletrônicos. Disponível em: $<$ www.portalrevistas.ucb.br> Acesso em: 10 de junho de 2015. p. 06-21.

PETRI, V.; SIVERIS, D.; DELEVATI, D.; RODRIGUES, N. R. Um outro olhar sobre o dicionário: a produção de sentidos. 1. ed. Santa Maria: PPGL-Editores, 2010. v. 1. 120 p. Disponível em: $<\mathrm{http}: / /$ corpus.ufsm.br/?p=140>. Acesso em: 12 de junho de 2015.

REAL ACADEMIA ESPAÑOLA DE LA LENGUA. Diccionario de la Lengua Española. (23 ${ }^{\mathrm{a}}$. ed.) Madrid: Espasa Calpe, 2014.

. Sítio Web de la Real Academia Española de la Lengua - Información. Disponível em: $\overline{<\mathrm{http}} / / / \mathrm{www}$. rae.es/la-institucion/presentacion/informacion>. Acesso em: 10 de julho de 2015.

RODRIGUES, R.S.V. Saussure e a definição da língua como objeto de estudos. ReVEL. Edição especial n. 2, 2008.

SAUSSURE, F (1916). Curso de Linguística Geral. 27ª ed. São Paulo: Cultrix, 2006.

SAUSSURE, F (1916). Curso de Linguística Geral. 28ª ed. São Paulo: Cultrix, 2012. 